\title{
Sekolah Pesisi Juang: Pendidikan Non-Formal Anak Pesisir
}

\author{
Sepma Pulthinka Nur Hanip \\ Interdisciplinary Islamic Studies, UIN Sunan Kalijaga, Yogyakarta \\ Email: shevahanip182@gmail.com \\ A. Munawwir \\ Interdisciplinary Islamic Studies, UIN Sunan Kalijaga, Yogyakarta \\ Email: lancing.brumbung@gmail.com
}

\begin{abstract}
Abstrak
Studi ini betujuan menganalisis kiprah sekolah pesisi juang sebagai pendidikan non-formal yang mengadopsi sistem pembelajaran tematik sebagai upaya untuk memberikan pemenuhan kebutuhan intelektual secara universal bagi anak pesisir yang berlokasi di Desa Bintaro, Kecamatan Ampenan Nusa Tenggara Barat. Metode penelitian yang digunakan adalah pendekatan kualitatif dengan menggunakan pisau analisis psikologi humanistik yang difokuskan pada kebutuhan manusia secara subtansial. Metode pengumpulan data yang digunakan berupa observasi, wawancara, dan dokumentasi. Analisis data mengacu pada kerangka Miles dan Huberman yang didasari pada reduksi data, penyajian data, dan penarikan kesimpulan. Hasil penelitian ini membuktikan bahwa, anak pesisir berhak untuk menerima pendidikan secara formal seperti yang lainnya walaupun dihimpit dalam ekonomi yang kurang mampu. Hadirnya sekolah pesisi juang ini menjadi angin segar bagi anak pesisir untuk terus belajar dalam menggapai cita-citanya dengan mengajarkan anak-anak muatan-muatan pemebalajaran berbasis lingkungan sekitar.
\end{abstract}

Kata kunci: Sekolah Pesisi Juang, Anak Pesisir, Pendidikan Non Formal

\begin{abstract}
This study aims to analyze the progress of the pesisi juang schools as non-formal education that adopts a thematic learning system as an effort to provide universal intellectual needs for coastal children located in Bintaro village, Ampenan district, NTB. The research method used is a qualitative approach using humanistic psychological analysis that focuses on human needs substantially. The data collection methods used were observation, interview and documentation. Data analysis refers to the Miles and Huberman framework which is based on data reduction, data display, and conclusions drawing. The results of this study prove that, coastal children have the right to receive formal education like others even though they are squeezed into a less fortunate economy. The presence of this pesisi juang school is a breath of fresh air for coastal children to continue learning in achieving their dreams by teaching children learning materials based on the surrounding environment.
\end{abstract}

\section{PENDAHULUAN}

Pendidikan merupakan hal yang paling penting dalam proses kehidupan umat manusia yang membedakannya dengan makhluk ciptaan yang lain. Tanpa pendidikan, manusia tak akan disebut sebagai makhluk yang cerdas, pembuat alat, dan bahkan menjadi makhluk yang bijak. Vygotsky berkeyakinan, pendidikan merupakan proses pengembangan pengetahuan dan pemahaman terhadap realitas sosial (Long, 2011:166).
Selain itu, pendidikan juga dapat memberikan pengalaman yang bermakna dan membekas di hati sebagai stimulus yang mencakup segala bidang kehidupan (Komar, 2006:23).

Menghadapi dunia yang kompetitif, pendidikan adalah senjata utama yang digunakan sebagai jalan untuk kelangsungan hidup dan ukuran kualitas diri. Pendidikan juga sebagai pengetahuan yang berfungsi menjadi vitamin menuju kesuksesan yang menghasilkan daya saing dan mengarahkan ke hari esok yag lebih cerah. 
Bahkan, pendidikan merupakan sumber kekuatan untuk membebaskan manusia dari penjara kemiskinan, perampasan, stagnasi dan dekadensi (Bhatt, 2018:11).

Dari itu, pendidikan tidak hanya terjadi dalam ruang-ruang formal seperti di sekolah. Melainkan juga adanya bimbingan dari keluarga (informal), dan pendidikan nonformal yang juga harus menjadi pijakan untuk membentuk masa depan anak yang lebih maju demi mengembangkan aspek kognitif, afektif dan psikomotoriknya. Hal tersebut sesuai dengan pandangan $\mathrm{Ki}$ Hajar Dewantara tentang tri pusat pendidikan (Wiryopranoto, 2015:172).

Pendidikan dapat membentuk masa depan dunia yang lebih damai, adil, berkelanjutan, dan peduli diperlukan konstribusi pendidikan yang bercorak formal dan non-formal yang diperioritaskan untuk mengembangkan peserta didik (Power, 2006:71). Sekolah formal mencerminkan masyarakat sebagai bentuk pendidikannya. Namun pendidikan formal pada prinsipnya berkaitan dengan ranah kognisi yang bertujuan untuk mempengaruhi sikap, nilai, dan perilaku sosial dalam konteks yang lebih luas. Berbeda dengan sekolah yang bersifat non-formal yang pembelajarannya diselimuti dengan permainan, simulasi, dan realitas sosial konkrit yang terikat kepada tempat tinggal anak serta kebudayaan di lokasi tertentu (Bianco, 2006:213).

Gerbang utama menuju kesuksesan harus ada keseimbangan antara tiga pusat Pendidikan. Walaupun begitu, pendidikan formal masih terbentur dengan masalah seperti pemerataan pendidikan, sarana dan prasarana, acuan mutu pendidikan nasional, pendidik dan tenaga kependidikan kurang inovatif, dan terlebih mahalnya biaya pendidikan. Selain itu, Pendidikan dalam keluarga belum tentu dapat dirasakan oleh anak yang orang tuanya bekerja sepanjang hari untuk menghidupi ekonomi keluarga. Terlebih, pendidikan non-formal yang berbentuk lembaga bimbingan belajar yang memungut biaya tidak dapat dipenuhi bagi keluarga ekonomi rendah. Bagi keluarga yang ekonomi kelas menengah dapat memenuhi tuntutan tersebut. Hal ini tentu menjadi kekurangan bagi anak-anak pesisir untuk menatap masa depan yang lebih cerah.

Fenomena tersebut menggambarkan, hanya ekonomi keluarga yang menjadi patokan mutlak dan syarat utama yang harus terpenuhi sebagai sarana keberlangsungan pendidikan anak. Perekonomian memiliki kendali yang besar sebagai jalan utama mengembangkan intelektual yang berbanding lurus dengan harapan masyarakat agar anaknya mendapatkan pekerjaan yang layak. (Baharudin, 2014:64). Hal ini yang menjadi permasalahan mendasar masyarakat pesisir pantai yang hanya mengadalkan sumber daya alam sekitar untuk memenuhi kebutuhan ekonomi keluarga. Bergantung dengan relasi jual-beli yang didapat dari hasil laut. Hasil yang didapat diperuntukkan untuk kebutuhan sehari-hari dan pendidikan bagi anak-ananya agar maju dalam bidang kehidupan.

Mata pencaharian sebagai nelayan dan berdagang merupakan karakter sosial masyarakat pesisir yang merupakan struktur karakter sebagian besar anggota kelompok yang berkembang dan merupakan pengalaman keseharian dan gaya hidup yang umum terjadi. Karakter dalam pandangan psikologis merupakan bentuk tertentu dari dinamika kehidupan kelompok (Fromm, 2019:292).

Analisis dari beberapa literatur yang ada, kurangnya minat dan motivasi dalam belajar merupakan kendala utama bagi anak pesisir untuk terus melanjutkan pendidikan. Selain itu, tidak terjangkaunya bimbingan belajar dan pendidikan formal yang belum menyentuh realitas sosial menjadi penyebab rata-rata pendidikan yang ditempuh hanya 
sampai tingkah sekolah menengah atas atau kejuruan seperti kasus di kepulauan Madura, Donggala, Palu, Pulau Untung Jawa Kepulauan Seribu, DKI Jakarta dan Kuala Langsa, Aceh. Artinya bahwa, kualitas sumber daya manusia dapat ditentukan oleh tingkat Pendidikan. ( Mansyur, 2019:5; Amil, 2019:132; Masri, 2017:225; Ranti, 2018:22; Syafrillia, 2019:309).

Selain mata pencaharian yang bersumber dari laut sebagai akar ekonomi, keberlangsungan hidup untuk menciptakan masa depan yang lebih cerah harus ada sinergi pendidikan yang diperioritaskan memenuhi atribut formal dan non-formal untuk mengembangkan anak-anak pesisir yang orang tuanya hanya berharap kepada lembaga pendidikan yang bersifat formal. Dengan demikian, Pendidikan non-formal menjadi pintu solusi untuk mendapatkan pengalaman yang lebih luas. Selain itu, kendala utama yang dihadapi anak pesisir adalah minimnya fasilitas yang menunjang pendidikannya. Di saat orang lain belajar di rumah dengan fasilitas yang lengkap, anak pesisir belum mampu mendapatkan hal tersebut. Hadirnya sekolah pesisi juang yang berlokasi di Desa Bintaro Jaya, KecamatanAmpenan, Lombok, Nusa Tenggara Barat menjadi secercah harapan anak-anak pesisir untuk menimba Ilmu Pengetahuan dan bimbingan belajar tanpa pungutan biaya demi kemajuan dan motivasi agar menjadi lebih giat dan tak patah semangat.

Kiprah sekolah pesisi juang dan arah pendidikannya yang menganut sistem pembelajaran tematik, menentukan laju anakanak pesisir untuk menggapai cita-cita murni dengan ketentuan bagaiamana cara membimbing, mengarahkan, memotivasi, mengispirasi, dan memfasilitasi pembelajaran sebagai fungsi dari pendidik utuk membangkitkan potensi peserta didiknya. Sekolah yang bersifat non-formal berkomitmen, ekonomi bukan menjadi penghalang besar bagi anak pesisir yang bercita-cita menempuh pendidikan setinggitingginya karena telah banyak lembaga yang membuka beasiswa sebagai bantuan pendidikan. Dalam hal ini, psikologi humanistik dapat dijadikan sebagai bahan analisis bagaimana ekonomi mengendalikan kebutuhan manusia secara hirarkis termasuk dalam bidang pendidikan yang merupakan kebutuhan intelektual manusia.

Tujuan dari penelitian ini tidak ada lain kecuali hanya untuk memotivasi anak-anak pesisir yang secara ekonomi dan akses pendidikan sangat terbatas. Adanya pendidikan non-formal yang menjadi tempat mereka untuk belajar menjadi bukti bahwa pendidikan tidak harus selalu terjadi dalam tempat-tempat formal, sebagaimana yang sudah banyak diketahui selama ini. Pendidikan non-formal juga bisa menjadi tempat nyaman bagi mereka, sehingga memungkinkan terjadinya transfer of kwnoledge. Dengan begitu, tidak berlebihan, jika pendidikan non-formal pada hakikatnya, sama dengan pendidikan formal. Yang membedakan hanya pada persoalan tempat, ruang, dan aturan yang amat sangat kompleks.

\section{METODE}

Metode penelitian yang digunakan adalah kualitatif dengan pendekatan studi kasus (case study). Studi ini adalah hasi ijtihad dari Creswell. Menurutnya, studi kasus adalah jenis studi yang berupaya untuk mengeksplorasi lebih jauh sistem-sistem yang berkaitan (bounded system). Penggunaan studi ini biasanya dikarenakan memiliki arti penting bagi seseorang, atau paling tidak bagi peneliti. Sedangkan menurut Patton, arti penting dari studi kasus adalah manakala memiliki kompleksitas yang ingin dipahami secara utuh dalam konteks waktu dan situasi tertentu (Raco, 2010:49). 
Adapun pengumpulan data melalui tiga teknik: pertama observasi. Observasi bisa diartikan sebagai pengamatan secara rinci terkait tingkah laku, interaksi, kejadian, dan situasi (Agusta, 2003:01). Kedua wawancara. Wawancara digunakan sebagai upaya untuk mengumpulkan beberapa data penting dari informan yang telah ditentukan. Teknik ini diharapkan mampu memberikan banyak informasi tentang sekolah pesisi juang yang diperuntunkan untuk anak-anak pesisir. Dan yang ketiga dokumentasi. Di samping observasi dan wawancara, teknik dokumentasi juga sangat membantu untuk mendapatkan data-data yang tersimpan, semisal baik dalam bentuk jurnal kegiatan, arsip, dokumen, catatatn harian, dan lain sebagainya (Rahardjo, 2011:04). Sedangkan analisis data merujuk pada apa yang diuraikan oleh Milles dan Huberman, yaitu, reduksi data, penyajian data, dan pengambilan kesimpulan.

\section{HASIL}

Sekolah Pesisi juang berdiri atas inisiatif Saudara Jauhari Tantowi dan temantemannya yang berdiri pada bulan Mei 2020 sebagai sebuah pendidikan non-formal yang dibangun bagi anak-anak pesisir di Desa Bintaro Jaya sebagai wadah bimbingan belajar. pesisi merupakan ungkapan bahasa suku Sasak, Lombok yang berarti pesisir. Sedangkan juang memiliki makna filosofi yang artinya perjuangan yang ditujukan untuk anak pesisir agar berjuang untuk terus belajar, menggapai cita-cita dan dapat menerima pendidikan secara utuh walaupun diterpa dengan rendahnya ekonomi. sekolah pesisi juang dibangun dengan cinta dan kedekatan hati, dimana tidak ada manusia yang menginjak sesama manusianya.

Lembaga ini memiliki jumlah siswa sekitar 58 orang yang terdiri dari anak yang belum sekolah hingga sekolah menengah (SMP) yang masing-masing dibagi menjadi dua kelas. Kelas A dari yang belum menempuh pendidikan berkumpul dengan anak yang sampai pada kelas 4 SD. Kelas B dimulai dari anak kelas 5 SD sampai pada kelas SMP dengan cara terjadwal yang dilakukan pada setiap hari Kamis dan Minggu. Konsep pembelajaran yang digunakan sekolah pesisi juang ini menggunakan pembelajaran tematik-terpadu yang menekankan pada realitas kehidupan.

Konsep pendidikan humanistik menjadi pijakan dasar terbentuknya pendidikan bagi anak pesisir. Merujuk pada pandangan Freire, yang menolak bentuk dehumanisasi sebagai ajang perbudakan bagi kaum yang tertindas dalam pendidikan. Untuk menanggulanginya, dibutuhkan pendidikan yang bersifat memanusiakan manusia sebagai syarat mutlak eksitensi pendidikan (Freire, 2009:7). Prinsip humanistik dalam pendidikan bercorak antroposentris, belajar melalui pengalaman, bersifat kolaboratif, terbuka, dan membangun jati diri secara profesional (Goldstein \& Fernald, 2009:27).

Muatan pembelajaran sekolah pesisi juang mencakup membaca, menulis, serta permainan yang menyenangkan dengan cara berkelompok dan bermain dipinggir pantai sekaligus memberikan pembelajaran dengan memberikan pertanyaan apa saja yang ditemukan di sekitar pantai tersebut dan masalah apa saja yang ditemui. Lalu pendidik memberikan solusi dari masalah yang ditemukan disekitarnya. Terlebih, partisipasi secara rutin ini didukung oleh komunitas penerima beasiswa Bank Indonesia atau Genbi NTB sebagai tenaga pengajar yang terdiri dari Mahasiswa Universitas Mataram, UIN Mataram, Universitas Samawa, Sumbawa Besar dan Perhimpunan Kodokteran Luar Negeri Indonesia (PERLUNI) Tiongkok turut serta dalam proses pendidikan. 
Kerjasama antara sekolah pesisi juang dan Genbi NTB untuk melaksanakan program kerjanya yaitu sekolah darurat yang bertujuan untuk memperjuangkan hak anak-anak pesisir untuk melanjutkan pendidikan. Dalam bidang kesehatan, PERLUNI Tiongkok ikut berpartisipasi dan sekaligus turut serta dalam kegiatan belajar mengajar. Kondisi ini merupakan angin segar bagi anak pesisir untuk mendapatkan motivasi bagaiamana meraih cita-cita untuk tetap bersekolah walaupun dalam keadaan ekonomi yang serba kurang. Terlebih di masa Pendemi Covid-19, anak-anak pesisir yang belajar di rumah merasa kesulitan untuk mendapat bimbingan belajar dari orang tua karena kesibukan dalam nelayan, dan pekerjaan lainnya. Yang biasanya orang lain belajar dari rumah dengan fasilitas yang lengkap, bagi anak pesisir, ketiadaan fasilitas merupakan kendala utama selama ini.

Sistem pembelajaran yang digunakan adalah sistem pembelajaran kooperatuf. Sistem ini atau yang biasa disebut dengan mitra-mitra dalam pembelajaran bertujuan untuk mengajarkan siswa agar saling bekerja sama dalam menyelesaikan tugas atau masalah dan untuk membangun skill sosial siswa serta meningkatkan hasil pembelajaran.

Sedangkan role playing berbeda dengan kinerja yang lainnya sebagai salah satu jalan yang penting untuk mengenali fakta. Yang terpenting, role playing bergulat dalam latihan permainan peran sebagai praktik alaminya. Hal ini bertujuan untuk menghasilkan suatu kerja yang maksimal walapun terdapat kesalahan dalam pecobaan. Sebaliknya seseorang didorong untuk bermain secara serius, mengeksplorasi dan menemukan cara baru untuk memenuhi tuntunan dengan cara yang profesional (Heinrich, 2018:34). Sehingga perlunya peserta didik dalam memainkan peran yang didapat dari simulasi untuk dipertunjukkan sebagai latihan perilaku agar dapat dibiasakan di kehidupan sehari-hari.

Kegiatan role playing/bermain peran dengan menggunakan skenario yang telah disediakan oleh guru yag diperankan secara seksama misalnya dengan tema "Jangan membuang sampah sembarangan" akan diperagakan dengan cara salah satu murid yang membuang sampah tidak pada tempatnya. Kemudian salah satu murid lagi menegur dengan cara yang baik dan sopan dengan mengatakan "Mohon maaf, jangan membuang sampah sembarangan. Buanglah sampah pada tempatnya". Selain itu, masih ada tema juga tentang bagaimana menjadi seseorang yang jujur.

Beberpa model pembelajaran tersebut merupakan pendekatan yang sering digunakan di sekolah pesisi juang tersebut sebagaimana karakter anak pesisir yang bergelut dengan alam, selalu berkelompok dalam bermain, dan terlebih rasa kebersamaan yang selalu dijalani setiap harinya. Dengan begitu, pendidikan diarahkan ke dalam hal yang menyenangkan dan bermakna untuk menghayati realitas sekitarnya.

Dalam pendidikan anak pesisir, pembelajaran menggambar, berdongeng yang diiringi dengan menggunkan wayang yang bertema "Kejujuran" juga diterapkan di sekolah pesisi juang. Selain itu, hal yang perlu juga menjadi pembelajarannya adalah peduli tentang lingkungan. Setiap anak indonesia berhak mendapatkan pendidikan dan lingkungan yang baik. Sekolah pesisi juang mengadakan acara diskusi yang bertajuk "Apa Kabar Sampah" di Lapangan Bintaro, Ampenan pada hari Minggu 12 Juli 2020. Kegiatan ini atas inisitif pendidik ditujukan kepada peserta didik sendiri yang dikemas dengan performa yang menarik dan asyik, dialog dengan komunitas Nol Sampah, dan pengarahan dari kepala bidang pengelolaan sampah dan pengendalian pencemaran 
lingkungan Dinas LHK Provinsi NTB. Dengan kegiatan ini, harapan kedepannya menjadi jalan untuk membangun sistem khusus dalam penanganan sampah di Lingkungan Bintaro Ampenan. Sekaligus kegiatan ini sebagai titik awal menumbuhkan kesadaran masyarakat akan pentingnya mewarisi lingkungan yang asri dan lestari bagi generasi selanjutnya.

Manusia merupakan bagian dari lingkungan, sudah sewajarnya mampu merawatnya. Kepedulian terhadap lingkungan menjadi perhatian besar bagi anak pesisir di sekolah pesisi juang bagaimana menjaga dan mengelola alam sekitar tetap asri sebagai dasar dari pendidikan yang bermakna.

Pengalaman yang bermakna dalam pendidikan akan dihadapi dengan tidak secara terus menerus menjejali peserta didik dengan materi. Transfer pengetahuan dengan mengamati realitas konkrit dan terlaksanakannya kegiatan belajar mengajar yang menyenangkan dan kebebasan dalam berfikir untuk membangkitkan daya imajinasi kreatifnya dijadikan sebagai tolak ukur dalam pendidikan humanistik.

\section{PEMBAHASAN}

\section{Pendidikan Vis a Vis Ekonomi}

Dunia modern dihadapi dengan perkembangan laju ekonomi yang menjadi sentral masyarakat untuk memenuhi segala kebutuhan hidup. Di sisi lain, pendidikan merupakan hak bagi manusia, namun tidak semua orang dapat kesempatan untuk berpendidikan. Informasi yang terekspos dari media cetak, online, dan televisi mewartakan kondisi pendidikan anak pesisir sangat memperihatinkan. Permasalahan mendasar yang dihadapi adalah faktor ekonomi yang rendah dan akses pendidikannya yang begitu jauh dari lokasi tempat tinggal. Bahkan, anak pesisir dilibatkan oleh orang tua untuk mencari nafkah dan menopang kehidupan sehari-hari.

Ekonomi yang tidak sejalan dengan proses pembangunan sumber daya manusia akan mempengaruhi mentalitas manusia termasuk cara pandangnya tentang pendidikan. Sebaliknya, ekonomi yang seimbang akan mengantarkan manusia kepada pendidikan yang kritis yang mampu melihat perkembangan zaman berserta tantangantantangannya kedepan (Freire, 2001:41).

Jika merujuk pada hirarki kebutuhan Abraham Maslow, pemenuhan kebutuhan manusia memiliki hirarki dari yang paling rendah hingga yang paling tinggi. Aspek yang harus dipenuhi lebih utama berupa kebutuhan fisiologis yaitu makan dan minum. Jika aspek yang paling penting dalam kehidupan manusia tidak dapat terpenuhi, kebutuhan untuk aktualisasi diri akan terpinggirkan (Jarvis, 2018:94-95). Untuk mewujudkan hal tersebut, fenomena dunia modern untuk pemenuhan kebutuhan hirarkinya akan dikendalikan oleh faktor ekonomi termasuk juga pada kebutuhan intelektual yang dilakukan dalam ruang pendidikan.

Jika dicermati secara mendalam, anakanak pesisir juga memiliki kebutuhan yang sepenuhnya dapat diwujudkan jika perekonomian dapat diatasi. Pemenuhan kebutuhan untuk mengenyam pendidikan digambarkan ketika berangkat ke sekolah. Sebelum berangkat ke sekolah, setidaknya memenuhi kebutuhan awalnya yaitu, fisiologis. Ketika berangkat ke sekolah, menginginkan rasa aman sehingga dapat mengikuti pelajaran. Bertemu dengan temanteman di sekolah untuk memulai suatu instraksi sosial. Pergaulan dengan teman untuk mendapatkan rasa saling menghargai antar sesama. Ketika berada di dalam kelas untuk memulai pelajaran, membutuhkan intelektual. Memahami ilmu yang didapat di sekolah memberikan arti keindahan sehingga 
siswa terpacu untuk mengaktualisasikan dirinya dalam kehidupan nyata sesuai yang didapat dalam pembelajaran disekolah.

Walaupun secara ekonomis dapat teratasi, tugas selanjutnya yang dihadapi bagaimana menyeimbangkan pendidikan baik secara formal, informal, maupun nonformal untuk memuluskan cita-cita UU Sisdiknas No 20 Tahun 2003 tentang sistem pendidikan Nasional yang diartikan sebagai pendidikan adalah usaha sadar dan terencana untuk mewujudkan suasana belajar dan proses pembelajaran agar peserta didik secara aktif mengembangkan potensi dirinya untuk memiliki kekuatan spiritual keagamaan, pengendalian diri, kepribadian, kecerdasan, akhlak mulia, serta keterampilan yang diperlukan untuk dirinya, masyarakat, bangsa dan Negara.

Oleh sebab itu, Ki Hajar Dewantara sangat menekankan betapa pentingnya pendidikan. Pendidikan dapat mengubah arah bangsa secara historis. Pendidikan dapat mengubah kesadaran untuk berbangsa dan bernegara secara merdeka. Pendidikan juga mampu menjadikan manusia menjadi bahagia (Rahardjo, 2012:68).

untuk menopang pendidikan anak pesisir secara utuh, dibangunnya sekolah alternatif yang bersifat non-formal sebagai bentuk kepedulian dalam bimbingan belajar tanpa dalih biaya. Kendala ekonomi anak pesisir setidaknya dapat teratasi sekaligus sarana pemberian wawasan kepada orang tua betapa pentingnya pendidikan bagi anakanaknya. Salah satu pendidikan alternatif yang bernama sekolah pesisi juang tidak berjuang sendiri untuk memperjuangkan hak anak pesisir untuk mengenyam pendidikan. Komunitas Penerima Beasiswa Bank Indonesia (Genbi NTB), Perhimpunan Kedokteran Luar Negeri Indonesia (PERLUNI) Tiongkok, dan komuntas jalan baru turut hadir untuk mengajar dan belajar bersama serta turut memperjuangkan hak anak-anak pesisir untuk melanjutkan pendidikannya.

Dengan adanya dukungan dari segala pihak, ekonomi bukan lagi menjadi penghalang untuk menggapai cita-cita masa depan. selebihnya, minat dan perjuangan dalam belajar harus terus dipupuk sebagai kunci utama. Anak-anak pesisir tidak lagi turut serta memenuhi ekonomi keluarga. Pilihan yang harus diambil adalah mengejar cita-cita dengan belajar sungguh-sungguh dan berprestasi sebagai syarat menempuh beasiswa tanpa memikirkan kondisi ekonomi sebagai salah satu jalan keluar yang harus ditempuh.

\section{Sekolah Pesisi Juang: Arah Pendidikan dan Model Pembelajaran}

Memperhatikan proses pendidikan yang dihadapi oleh anak pesisir, kesadaran akan pendidikan merupakan hal yang begitu penting dan harus dilakukan dalam rangka transfer ilmu pengetahuan. Mengamalkan ilmu pengetahuan merupakan langkah aktualisasi diri. Dalam pandangan Alan Tom bahwasanya, mengajar merupakan tindakan moral dan secara otomatis belajar juga merupakan tindakan moral (Benninga, 2003:20).

Dalam konteks anak pesirir, konsep pendidikan humanistik menjadi pijakan. Arah pendidikan humanistik dijembatani oleh sistem pembelajaran tematik. Pembelajaran tematik terpadu merupakan konsep dasar dalam pelaksanaan proses pembelajaran pada Kurikulum 2013 yang telah diatur dalam Permendikbud Nomor 22 Tahun 2016 tentang standar proses. Adapun prinsip-prinsip pembelajaran tematik terpadu adalah peserta didik mencari tahu, pembahasan pembelajarannya mencari tema yang paling dekat dengan kehidupan yang berkaitan dengan berbagai konsep, keterampilan, dan 
sikap, dan memberikan pengalaman langsung kepada peserta didik. Tujuannya adalah untuk meningkatkan soft skill dan hard skill yang mencakup tiga ranah kompetensi yaitu kognitif, afektif, dan psikomotorik (Windarny \& Mustadi, 2019:3; Iasha, 2018:18).

Pendidikan non formal yang menganut pembelajaran tematik terpadu memiliki model pembelajaran sebagai penunjang kesuksesan belajar seperti simulasi, pengajaran sosial, dan bermain peran (role paying) yang lekat dengan kehidupan sehari-hari. Pengajaran sistem perilaku yang berbasis simulasi merupakan subuah ilustrasi yang dijadikan ceminan untuk aksi dengan seperangkat komitmen emosional terhadap permainan bagaimana mengeksplorasi secara alternatif apa yang dapat dilakukan, membenarkan pilihan yang sulit, berurusan dengan emosi yang sangat compleks, pemahaman yang mendalam tentang apa yang akan dilakukan kepada seseorang secara profesional (Counsell, 2014:164).

Terkadang role playing yang dilakukan saat latihan akan dihadapi oleh problem yang membingungkan peserta didik. Menurut hasil penelitian Suchman, cara semacam ini secara alamiah akan memotivasi siswa untuk menyelesaikan masalah tersebut. Di samping itu, juga meningkatkan pemahaman sains untuk berpikir kreatif, dan keterampilan dalam memperoleh dan menganalisis informasi (Mahulae, 2017:25).

Model pengajaran yang digunakan adalah model pengajaran sosial dengan bentuk mitra-mitra dalam pembelajaran atau yang sering disebut dengan pembelajaran kooperatif (cooperative learning). Model tersebut merupakan pembelajaran dengan sistem berkelompok yang membutuhkan kerja sama antar peserta didik. Sebagaimana Sanjaya mengungkapkan bahwa cooperative learning smerupakan kegiatan belajar siswa yang dilakukan secara berkelompok, sedangkan model pembelajaran kelompok itu sendiri adalah rangkaian kegiatan belajar yang dilakukan oleh siswa dalam kelompokkelompok tertentu untuk mencapai tujuan pembelajaran yang telah dirumuskan (Rusman, 2010:203).

Sekolah pesisi juang sangat memperhatikan alam dan lingkuangn sekitar. Dalam konteks pendidikan, membicarakan masalah-masalah tentang lingkungan merupakan suatu bentuk kesadaran akan pentingnya menjaga dan sebagai peringatan bagi manusia yang tidak tahu bahaya-bahaya degradasi lingkungan. Mengajak manusia kembali kepada penilaian hidup, menggunakan proses ilmu pengetahuan, dan melihat diri sendiri dalam hubungan dengan realitas sosial akan merubah cara pandang manusia melihat dunia (Freire, 2001:43).

\section{SIMPULAN}

Sarana utama untuk dapat membentuk masa depan Dunia adalah melalui pendidikan. Dalam setiap perjalanan kehidupan, manusia akan tetap dikelilingi oleh lingkaran pendidikan dimanapun dan kapanpun dan seharusnya dapat dinikmati oleh semua manusia.

Dalam kasus kecil ini, pendidikan untuk anak pesisir harus sesering mungkin untuk diperhatikan. Hadirnya sekolah pesisi juang sebagai Pendidikan non-formal bagi anak pesisir bekerja sama dengan berbagai pihak seperti di bidang kesehatan PERLUNI ( Perhimpunan Kedokteran Luar Negeri) Tiongkok dan bidang Pendidikan ada Genbi NTB (Komunitas Penerima Beasiswa Bank NTB) yang bertujuan untuk meningkatkan motivasi belajar dengan pembelajaran yang menyenangkan seperti menggambar, belajar melalui lingkungan sekitar, bermain peran, dongeng yang diiringi dengan permainan wayang, dan Pendidikan peduli lingkungan. 
Dengan begitu, semangat untuk terus belajar dapat dirasakan dengan kebahagiaan.

Penelitian ini menjadi bagian kecil dari tema besar pendidikan non-formal. Tentunya masih ada banyak di luar sana pendidikan non-formal yang juga perlu diteliti dan ditulis dengan baik, agar bisa dibaca oleh banyak orang. Tujuan akhirnya tidak lain, kecuali agar pemerintah juga memperhatikan pendidikan yang demikian, sehingga mereka yang belajar mendapatkan sesuatu yang menjadi haknya.

\section{DAFTAR RUJUKAN}

Agusta, Ivanovich. (2003). Teknik Pengumpulan dan Analisis Data Kualitatif, Bogor: Pusat Penelitian Ekonomi, Litbang Pertanian.

Amil, Ahmad Jamiul, Wulandari, Rika., \& Farahiba, Ayyu Subhi. (2019). Sakera

Seelok Dara "Sekolah Anak Pesisir Madura Sesuai Kearifan Lokal Budaya Madura" Sebagai Penguatan Pendidikan Non Formal Masyarakat Pesisir Pantai Madura. Jurnal Ilmiah Pangabdhi Vol. 05, No. 2, Oktober, 131-137.

Baharudin. (2014). Pendidikan dan Pengentasan Kemiskinan Masyarakat Nelayan Pesisir, Society: Jurnal Jursan Pendidikan IPS Ekonomi, Edisi xi, April, 57-67.

Benninga, Jaqques S., Berkowitz, Marvin W., Kuehn, Phyllis., \& Smith, Karen. (2003). The Relationship of Character Education Implementation and Academic Achievement in Elementary Schools, Journal of Research in Character Education, 1 (1), 19-32.

Bianco, Joseph Lo. (2006). Educating for Citizenship in a Global Community: World Kids, World Citizens and Global Education, dalam Jack Campbell, Nick Baikaloff \& Colin Power (Ed.),
Towards a Global Community: Educating for Tomorrow's World Global Strategic Directions for the Asia-Pacific Region, Netherlands: Springer.

Bhatt, Siddheshwar Rameshwar. (2018). Philosophical Foundations of Education Lessons for India, Singapore: Springer. Diambil pada tanggal 1 September $\quad 2020 \quad$ dari https://www.pdfdrive.com/

Counsell, Karen. (2014). Virtual Learning for the Real Word: Using Simulation with Non-law Student, dalam Caroline Strevens, dkk (Ed.), Legal Education: Simulation in Theory and Practice, England: Ashgate Publishing Limited. Diambil pada tanggal 1 September 2020 dari https://www.pdfdrive.com/

Freire, Paulo. (2001). Pendidikan Yang Membebaskan Terj. Martin Eran, Jakarta: Melibas.

(2007). Politik Pendidikan:

Kebudayaan, Kekuasaan, dan

Pembebasan, Terj. Agung Prihantoro \& Fuad Arif Fudiyartanto, Yogyakarta: Pustaka Pelajar.

Fromm, Erich. (2019). Lari Dari Kebebasan Terj. Noa Dhegaska, Yogyakarta: IRCiSoD.

GTK DIKDAS. Prinsip-Prinsip Pembelajaran Tematik Terpadu. (30, September 2019). Diambil pada Tanggal 22 September 2020 dari http://pgdikdas.kemdikbud.go.id/readnews/prinsipprinsip-pembelajarantematik-terpadu

Goldstein, Gary \& Peter Fernald. (2009). Humanistic Education In a Capstone Course, College Teaching, Winter, Vol. 57, No. 1, 27-36.

Heinrich, Paul.(2018) When Role-Play Comes Alive: A Theory and Practice, Singapore: Palgrave Macmillan. 
Diambil pada tanggal 1 September 2020 dari https://www.pdfdrive.com/

Iasha, Vina. (2018). Peningkatan Proses Pembelajaran Tematik Terpadu Menggunakan Pendekatan Scientific di Sekolah Dasar. AR-RIAYAH: Jurnal Pendidikan Dasar, Nol. 2, No. 1, 17-36. Jarvis, Matt. (2018). Teori-Teori Psikologi: Pendekatan Modern untuk Memahami Prilaku, Perasaan, dan Pikiran Manusia. Terj. SPA-Teamwork, Bandung: Nusa Media.

Komar, Oong. (2006). Filsafat Pendidikan Nonformal, Bandung: CV. Pustaka Setia.

Long, Martyn., wood, Clare., Littleton, Karen., Passenger, Terri., \& Sheehy. (2011). The Psychology of Education, New York: Routledge, 2011. Diambil pada tanggal 1 September 2020 dari https://www.pdfdrive.com/

Mansyur, Khumairah., Umrah, \& Rifal. (2019). Budaya Anak Pesisir di Wilayah Kepulauan Spermonde. Jurnal Pemikiran dan Pengembangan Belajar Vol. 1, No. 2, Mei-Agustus, 1-14.

Masri, Amiruddin. (2017). Pendidikan Anak Nelayan Pesisir Pantai Donggala. Asian Journal of Environment, History and Heritage, Vol. 1, Issue 1, September, 223-227).

Mahulae, Parno S., Sirait, Motlan., \& Sirait, Makmur. (2017). The Effect of Inquiry Training Learning Model Using Phet Media and Scientific Attitude on Students' Science Process Skills, IOSRJournal of Research \& Method in Education, Vol. 7, No. 5, SeptemberOktober, 24-29.

Power, Colin. (2006. Basic Education For All, dalam Jack Campbell, Nick Baikaloff \& Colin Power (Ed.), Towards a Global Community: Educating for Tomorrow's World
Global Strategic Directions for the Asia-Pacific Region, Netherlands: Springer.

Raco, J.R. (2010). Metode Penelitian Kualitatif: Jenis, Karakteristik dan Keunggulannya, Jakarta: Grasindo.

Rahardjo, Mudjia. (2011). Metode Pengumpulan Data Kualitatif. Malang: Universitas Maulana Malik Ibrahim Malang.

Rahardjo, Suparto. (2012). Ki Hajar Dewantara: Biografi Singkat 18891959, Jogjakarta: Ar-Ruzz Media.

Ranti, Gemala. (2018). Pengabdian Cakrawala Nusantara Untuk Membangkitkan Daya Saing Anak Pesisir melalui Pendidikan. ABDIMAS PEDAGOGI: Jurnal Ilmiah Pengabdian Kepada Masyarakat, Vol. 2, No. 1, Oktober, 21-27.

Rusman. (2010). Model-model Pembelajaran Mengembangkan Profesionalisme Guru, Jakarta: RajaGrafindo Persada.

Syafrillia, Tria., Asnawati., Mayangsari, Ajadesi., Fahlevi, Muhammad Andi., \& Maytina, Niar. (2019). Edukasi Masyarakat Pesisir Kuala Langsa Melalui Media Pembelajaran Berbasis Sumber Daya Hayati Lokal. Pros. SemNas. Peningkatan Mutu Pendidikan, Volume. 1, Nomor. 1, Desember, 309312.

Windarny, Denty \& Ali Mustadi. (2019). Pengembangan Lectora dalam Pembelajaran Tematik-Integratif Untuk Meningkatkan Prestasi Belajar Kognitif dan Karakter Siswa Sekolah Dasar. Jurnal Pendidikan Karakter, Tahun IX, Nomor. 1, April, 12-30.

Wiryopranoto, Suhartono., Herlina, Nina., Marihandono, Joko., dan Tangkilisan, Yuda B.,. (2015). Perjuangan Ki Hajar Dewantara: Dari Politik ke Pendidikan, 
Kementerian

Pendidikan

dan

Kebudayaan. 